\title{
Article
}

\section{Differential Leukocyte and Platelet Profiles in Distinct Models of Traumatic Brain Injury}

\author{
William Brad Hubbard ${ }^{1,2,3,4}\left(\mathbb{D}\right.$, Meenakshi Banerjee ${ }^{5,+}\left(\mathbb{D}\right.$, Hemendra Vekaria $^{1}(\mathbb{D}$, Kanakanagavalli \\ Shravani Prakhya ${ }^{5}$, Smita Joshi ${ }^{5}$, Qing Jun Wang ${ }^{6}$, Kathryn E. Saatman ${ }^{1,2}$, Sidney W. Whiteheart ${ }^{4,5}$

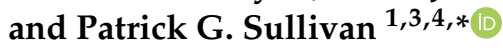

check for updates

Citation: Hubbard, W.B.; Banerjee, M.; Vekaria, H.; Prakhya, K.S.; Joshi, S.; Wang, Q.J.; Saatman, K.E.; Whiteheart, S.W.; Sullivan, P.G. Differential Leukocyte and Platelet Profiles in Distinct Models of Traumatic Brain Injury. Cells 2021, 10, 500. https://doi.org/10.3390/ cells10030500

Academic Editor: Yidong Bai

Received: 20 November 2020

Accepted: 18 February 2021

Published: 26 February 2021

Publisher's Note: MDPI stays neutral with regard to jurisdictional claims in published maps and institutional affiliations.

Copyright: (c) 2021 by the authors. Licensee MDPI, Basel, Switzerland. This article is an open access article distributed under the terms and conditions of the Creative Commons Attribution (CC BY) license (https:// creativecommons.org/licenses/by/ $4.0 /)$.
1 Spinal Cord and Brain Injury Research Center (SCoBIRC), University of Kentucky, Lexington, KY 40536, USA; bradhubbard@uky.edu (W.B.H.); hemendravekaria@uky.edu (H.V.); k.saatman@uky.edu (K.E.S.)

2 Department of Physiology, University of Kentucky, Lexington, KY 40508, USA

3 Department of Neuroscience, University of Kentucky, Lexington, KY 40508, USA

4 Lexington Veterans' Affairs Healthcare System, Lexington, KY 40502, USA; whitehe@uky.edu

5 Department of Molecular and Cellular Biochemistry, University of Kentucky, Lexington, KY 40536, USA; meenakshi.banerjee@utah.edu (M.B.); shravani.prakhya@uky.edu (K.S.P.); smita.joshi@uky.edu (S.J.)

6 Department of Ophthalmology and Visual Sciences, University of Kentucky, Lexington, KY 40536, USA; qingjun.wang@uky.edu

* Correspondence: patsullivan@uky.edu; Tel.: +1-859-323-4684

+ Current address: Department of Internal Medicine and Molecular Medicine Program, University of Utah, Salt Lake City, UT 84112, USA.

\begin{abstract}
Traumatic brain injury (TBI) affects over 3 million individuals every year in the U.S. There is growing appreciation that TBI can produce systemic modifications, which are in part propagated through blood-brain barrier (BBB) dysfunction and blood-brain cell interactions. As such, platelets and leukocytes contribute to mechanisms of thromboinflammation after TBI. While these mechanisms have been investigated in experimental models of contusion brain injury, less is known regarding acute alterations following mild closed head injury. To investigate the role of platelet dynamics and bioenergetics after TBI, we employed two distinct, well-established models of TBI in mice: the controlled cortical impact (CCI) model of contusion brain injury and the closed head injury (CHI) model of mild diffuse brain injury. Hematology parameters, platelet-neutrophil aggregation, and platelet respirometry were assessed acutely after injury. CCI resulted in an early drop in blood leukocyte counts, while $\mathrm{CHI}$ increased blood leukocyte counts early after injury. Platelet-neutrophil aggregation was altered acutely after CCI compared to sham. Furthermore, platelet bioenergetic coupling efficiency was transiently reduced at $6 \mathrm{~h}$ and increased at $24 \mathrm{~h}$ post-CCI. After CHI, oxidative phosphorylation in intact platelets was reduced at $6 \mathrm{~h}$ and increased at $24 \mathrm{~h}$ compared to sham. Taken together, these data demonstrate that brain trauma initiates alterations in platelet-leukocyte dynamics and platelet metabolism, which may be time- and injury-dependent, providing evidence that platelets carry a peripheral signature of brain injury. The unique trend of platelet bioenergetics after two distinct types of TBI suggests the potential for utilization in prognosis.
\end{abstract}

Keywords: neutrophil; platelet-neutrophil aggregate; bioenergetics; Seahorse; respirometry; controlled cortical impact; mild TBI

\section{Introduction}

Traumatic brain injury (TBI) continues to be a significant world-wide clinical problem that affects millions of individuals each year. While there remains a lack of FDA-approved pharmaceuticals for TBI treatment, the on-going understanding of the underlying pathobiology of head trauma not only identifies therapeutic targets but also pinpoints new avenues for TBI prognosis. Distinct pathological hallmarks, such as mitochondrial deficits and vascular damage, have been identified as major mechanisms of TBI [1-7]. Early bloodbrain barrier (BBB) impairment propagates interaction and infiltration of blood cells within 
the brain parenchyma, a process that is tightly regulated by the highly selective barrier under normal conditions [8]. After TBI, platelets and leukocytes attach to the vascular walls and aggregate in the injured cerebral tissue while also inducing inflammatory and immune responses [9-11]. Indeed, we have described BBB dysfunction following TBI as the epicenter for mechanisms of inflammation and thrombosis, which are mediated in part by platelets and leukocytes [12]. Thromboinflammation is among a variety of systemic pathologies that are now widely appreciated as potential consequences of TBI.

Alterations of platelet physiology have been reported clinically following severe TBI. Platelet dysfunction, characterized by inhibition of platelet arachidonic acid (AA) and ADP receptors leading to lower levels of AA/ADP-induced platelet activation, occurs early after severe TBI without major systemic trauma [13,14]. This inhibition appears to be dependent on TBI severity, with mild TBI demonstrating lower levels of platelet receptor inhibition [15]. TBI, by itself, results in increased bleeding time, or hypocoagulation, early after injury, which is indicative of deficits in coagulation pathways or platelets' ability to activate [14]. TBI also results in AA platelet receptor downregulation in the first few days following injury [16]. Importantly, there are shifts between hypocoagulable and hypercoagulable states following TBI [17]. Preclinical studies recapitulated these findings in murine models of moderate-to-severe TBI. These studies demonstrate immediate hypocoagulation followed by delayed hypercoagulation events [18-22]. Recently, one preclinical study showed changes acutely after closed head injury $(\mathrm{CHI})$, demonstrating hypercoagulability and increased aggregation of platelets at $6 \mathrm{~h}$ after $\mathrm{CHI}$ [19]. It is important to understand platelet dynamics to fully appreciate mechanisms of thromboinflammation.

Several neurodegenerative diseases and pathologies have utilized platelet function as a biomarker of injury progression. Platelet respiration is an emerging pathological biomarker as it can serve as a systemic marker for underlying mitochondrial dysfunction in metabolic tissues, such as the brain [23]. The concept that mitochondrial function in platelets can exemplify deficits in cerebral bioenergetics during neurological disease progression is not entirely new [24]; early work showed that Complex I activity is reduced in platelets of patients with idiopathic Parkinson's disease [25]. Furthermore, this has been appreciated in the context of Alzheimer's disease (AD) through decreased Complex IV activity in platelets of AD patients [26,27]. Maximal respiratory capacity in platelets correlates with respiratory control ratio (RCR) of mitochondria in skeletal and cardiac muscle [28] in addition to the brain [29]. Furthermore, changes in platelet coupling efficiency after cardiac arrest have been shown to represent underlying cerebral bioenergetic dysfunction [30]. We have shown acute mitochondrial impairment following both single and repeated mild TBI [2] and metabolic deficiencies that continue long-term following mild TBI [1]. Although platelet respiration shows promise as a peripheral monitor of neurodegenerative disease, no research, to date, has examined platelet bioenergetics within the context of TBI.

TBI presents clinically in a highly heterogeneous fashion, in terms of severity, symptomatic onset/progression, and underlying pathology. Even TBIs that are classified under the same Glasgow Coma Scale (GCS) score vary widely in terms of underlying pathology [31]. The pathologies and secondary injury mechanisms consist of multiple endophenotypes, such as bioenergetic dysfunction, vascular damage, and thromboinflammation. Therefore, injury-associated markers are necessary to systematically monitor these endophenotypes and, therefore, specific aspects of neurologic injury and recovery. This is also crucial in the context of repetitive mild head injury. Since repeated mild TBI results in worsened or prolonged outcomes [32], it is pertinent to track recovery following a mild TBI. Current return-to-play and return-to-duty guidelines for athletes and military service members, respectively, are put in place to prevent the additive effects of head trauma [33]. These are based upon memory recall and concentration compared with baseline assessments. However, cognitive recovery and symptom resolution do not necessarily equate to neuronal recovery [34]. Therefore, objective biomarkers that mirror deficits in cerebral metabolism after mild TBI are needed to assess sufficient brain recovery. We, therefore, focused on 
platelet function to further our understanding of metabolic alterations systemically after head trauma.

There are several characterized preclinical models of TBI that focus on replicating certain distinct aspects of clinical TBI. In the current study, we focus on head injury models that induce brain injury via compressive mechanical force. Other preclinical models, such as the closed-head impact model of engineered rotational acceleration (CHIMERA), involve shear deformation forces generated by rapid acceleration/deceleration of the head, which is a component of human TBI. Nevertheless, these compressive injury models indeed replicate clinical aspects of TBI-induced outcomes, such as behavioral deficits, axonal injury, inflammation, and metabolic dysfunction [2,35-38]. The controlled cortical impact (CCI) model involves impact directly to the dura of the brain producing a relatively defined, focal cortical contusion that results in cortical and hippocampal neurodegeneration at the site of injury. CCI can be graded in terms of severity by modifying the parameters of impact, namely depth of piston entry into the brain parenchyma. CCI produces mitochondrial dysfunction, neuroinflammation, neuronal death, and intracerebral hemorrhage. The $\mathrm{CHI}$ model involves a midline impact to the skull, which generates a relatively diffuse brain injury that produces neuroinflammation and deficits in brain metabolism. CHI typically does not produce overt brain hemorrhage or cell death.

To examine blood cell changes after TBI, we utilize these two distinct models of experimental brain injury to monitor the acute profile of leukocyte and platelet activity. We hypothesize that blood cell dynamics are altered transiently following TBI, in a manner dependent upon injury model. Furthermore, alterations in blood cell dynamics can impart understanding of mechanisms of thromboinflammation and coagulopathy.

\section{Materials and Methods}

\subsection{Experimental Design}

All of the studies performed were approved by the University of Kentucky Institutional Animal Care and Use Committee (IACUC). Additionally, the Division of Laboratory Animal Resources at the University is accredited by the Association for the Assessment and Accreditation for Laboratory Animal Care, International (AAALAC, International) and all experiments were performed within its guidelines. All animal experiments complied with ARRIVE (Animal Research: Reporting of In Vivo Experiments) guidelines and experiments were carried out in accordance with the National Institutes of Health Guide for the Care and Use of Laboratory Animals (NIH Publications No. 8023, 8th edition, revised 2011). All experiments were conducted using male C57BL/6J mice (2-3 months old; Jackson Laboratories, Bar Harbor, ME).

Animals were randomly assigned to groups and all data analyses were performed blinded to treatment groups. Experimental groups were euthanized at either 6 or $24 \mathrm{~h}$ after TBI or sham injury. The animals were housed five per cage and maintained in a $14 \mathrm{~h}$ light $/ 10 \mathrm{~h}$ dark cycle. All animals were fed a balanced diet ad libitum and water was reverse osmosis-generated. For all outcomes, experiments were conducted with biological replicates of $n=5-10$ /group. Additionally, technical triplets were used in each assay.

\subsection{Controlled Cortical Impact}

The CCI procedure was performed according to past studies [35,36]. Prior to injury, animals were anesthetized using 2-5\% isoflurane and their heads were shaved and placed in a Kopf stereotaxic frame for proper positioning under a pneumatic impactor (TBI-0310 Impactor, Precision Systems and Instrumentation (PSI), Fairfax, VA, USA). The animals body temperature was maintained at $37^{\circ} \mathrm{C}$ with the use of an isothermal pad. Artificial tears were placed in their eyes and anesthesia was maintained at 2-3\% isoflurane during the procedure. Prior to scalp incision, the scalp was cleaned with betadine and $200 \mu \mathrm{L}$ of a $10 \%$ local anesthetic in saline solution (Sensorcaine-MPF (Bupivacaine $\mathrm{HCl}$ ) $0.5 \%$ (Henry Schein Animal Health, Dublin, OH, USA) and Epinephrine 1:200,000) was injected subcutaneously at the site. A 3-mm craniotomy was performed lateral to the midline on the 
left side of the skull centered between lambda and bregma, without disrupting the dura. CCI groups received a unilateral injury, classified as severe $(1.0 \mathrm{~mm}$ depth of contusion at $3.5 \mathrm{~m} / \mathrm{sec}$ with a dwell time of $500 \mathrm{msec}$ ), directly to the surface of the brain using a $2 \mathrm{~mm}$ impactor tip. Sham animals received a craniotomy but did not receive an impact to the brain. Following the injury, the craniotomy was covered with an absorbable hemostat (Surgicel), followed by a sterilized plastic surgical cap, and incisions were then closed with surgical staples. Mice were taken off isoflurane exposure and were removed from the stereotaxic frame. Mice were then placed in a clean cage that was temperature-controlled at $37^{\circ} \mathrm{C}$ with a heating pad until the animals were mobile and fully responsive.

\subsection{Closed Head Injury}

Mice were subjected to $\mathrm{CHI}$ based on previous studies [2,39]. Following induction of anesthesia in a chamber using 3\% isoflurane for 1-2 min and shaving of the head, mice were transferred into a stereotaxic frame with non-rupture Zygoma ear cups (Kopf, Instruments, Tujunga, CA, USA) where anesthesia was maintained using $2.5 \%$ isoflurane delivered via a nose cone. The surgical area of the scalp was cleaned with a betadine solution. Following injection of $0.2 \mathrm{~mL} \mathrm{1:200,000} \mathrm{epinephrine} \mathrm{and} 0.5 \%$ bupivacaine in sterile, normal saline for local analgesia, the scalp was resected. Mice then received a mild CHI using a pneumatically controlled cortical impact device (TBI-0310 Impactor, PSI) with a custom made, $5 \mathrm{~mm}$ diameter, pliant, silicone tip with a hardness of 55 Shore A. The tip was aligned along the midline suture between the bregma and lambda sutures with the edge of the tip lined up with the lambda suture. The device was programmed to impact at an intended depth $(2.0 \mathrm{~mm})$ at a $3.5 \mathrm{~m} / \mathrm{sec}$ velocity with a $500 \mathrm{msec}$ dwell time. Sham-injured mice received anesthesia and underwent the same surgical procedure without receiving an impact. The total duration of anesthesia was controlled for all animals to be $10 \mathrm{~min}$. To assess loss of consciousness, mice were immediately removed from the stereotaxic device after impact and placed onto a heating pad on their backs. Apnea duration and time to right spontaneously to a prone position (righting reflex) were assessed. After righting, mice were briefly re-anesthetized to suture their scalps and returned to the heating pad to fully recover. Mice were injected (subcutaneous; s.c.) with $1 \mathrm{~mL}$ of sterile, normal saline to increase hydration, encouraging a normal eating response post-injury and maintenance of healthy weight.

\subsection{Mouse Platelet Isolation}

At either $6 \mathrm{~h}$ or $24 \mathrm{~h}$ post-injury, animals were asphyxiated with $\mathrm{CO}_{2}$, and up to $1 \mathrm{~mL}$ blood was collected via cardiac puncture. Blood was harvested using final concentrations of $0.38 \%$ sodium citrate solution (supplemented with $0.2 \mathrm{U} / \mathrm{mL}$ apyrase and $10 \mathrm{ng} / \mathrm{mL}$ prostacyclin $\left(\mathrm{PGI}_{2}\right.$ ) (Cayman Chemical, Ann Arbor, MI, USA; Cat \#18220)) in a 26G 3/8 syringe. Approximately $100 \mu \mathrm{L}$ of whole blood was taken for hematology counts and platelet-neutrophil aggregation (PNA) assays, while the remaining volume was used for isolating platelets for Seahorse analysis. The $2 \mathrm{~mL}$ tube, containing blood for Seahorse analysis, was centrifuged at $100 \times \mathrm{g}$ for $10 \mathrm{~min}$ at room temperature (RT; 20 to $25^{\circ} \mathrm{C}$ ). After centrifugation, the top yellow layer (platelet-rich plasma; PRP) was removed, being careful not to take the thin buffy coat layer or dark red RBC layer, and transferred into $1.5 \mathrm{~mL}$ tubes. The $1.5 \mathrm{~mL}$ tubes were centrifuged at $100 \times g$ for $10 \mathrm{~min}$ at RT. The supernatant (PRP) was removed and transferred to $1.5 \mathrm{~mL}$ tubes. Prostacyclin $\left(\mathrm{PGI}_{2} ; 30 \mu \mathrm{L}\right)$ was freshly added from a stock solution (prepared as $1 \mathrm{mg} / \mathrm{mL} \mathrm{PGI}_{2}$ in $50 \mathrm{mM}$ Tris, $\mathrm{pH}$ 9.5) to a phosphate/glucose buffer ( $50 \mathrm{~mL} 1 \mathrm{X}$ PBS, $45 \mathrm{mg}$ glucose $(5 \mathrm{mM})$ ) at time of assay. This phosphate-prostaglandin-glucose buffer (PPG) was added to increase the volume of PRP four-fold and mixed gently with a pipette. The samples were centrifuged at $2000 \times g$ for $1 \mathrm{~min}$ at RT. The tubes were then gently rotated and centrifuged again $2000 \times g$ for $5 \mathrm{~min}$ at RT. The supernatant (plasma) from this spin was removed with a pipette. The remaining platelet pellets were resuspended in $1 \mathrm{~mL}$ of PPG buffer and then the tubes were topped off with PPG buffer. The tubes were then centrifuged at $2000 \times g$ for $1 \mathrm{~min}$ 
at RT, rotated and centrifuged again at $2000 \times g$ for 2 min at RT. The supernatant from this last spin was removed and discarded and the pellet resuspended in $50 \mu \mathrm{L}$ PPG buffer. Protein concentration was determined using BCA protein assay kit (Pierce, Cat \# 23,227) recording the absorbance at $560 \mathrm{~nm}$ on Biotek Synergy HT plate reader (Winooski, VT, USA). Approximately $1 \mu \mathrm{g}$ platelet protein corresponds to $\sim 1 \times 10^{6}$ platelets, for which platelet counts were measured using a Z2 Coulter Counter (Beckman Coulter, Inc., Miami, FL, USA).

\subsection{Hematology Analysis}

Of the aliquoted $100 \mu \mathrm{L}$ of whole blood, $50 \mu \mathrm{L}$ was used to perform whole blood counts, including red blood cells, white blood cells (leukocytes), platelets, and mean platelet volume, using the IDEXX ProCyte Dx analyzer (IDEXX Laboratories, Westbrook, ME, USA).

\subsection{Flow cytometry - Platelet-Neutrophil Aggregation}

The remaining $50 \mu \mathrm{L}$ of whole blood was taken for fluorescence-activated cell sorting (FACS) studies. This assay was performed on live cells the day of blood collection. Whole mouse blood was incubated with FITC-anti-CD41/61 (platelets) and APC-anti-Ly6G (neutrophils) antibodies for $30 \mathrm{~min}$ at RT (see Figure S2 for gating strategy). To lyse the red blood cells, $1 \mathrm{~mL}$ of 1X BD FACS/Lyse Solution (BD Biosciences, San Jose, CA, USA; Cat No. 349202) was added to samples and incubated for 15 min at RT in dark. From this, $100 \mu \mathrm{L}$ was resuspended in $1 \mathrm{~mL}$ of PBS pH 7.4 and samples were analyzed on the BD LSRIITM flow cytometer (BD Biosciences) and 500,000 events were acquired per sample with gating around 50,000 granulocytes. Data were then analyzed using the FlowJo software (v7.6.5; BD Biosciences). Quantification shows PNAs as measured by double-positive events for both CD41/61 and Ly6G. Platelet-neutrophil dynamics were measured as: (\% double-positive events at $24 \mathrm{~h}$ post-injury) minus (\% double-positive events at $6 \mathrm{~h}$ post-injury).

\subsection{Measurement of Mouse Platelet Bioenergetics}

One previous report demonstrated that pooling whole blood from up to five mice would provide sufficient platelet numbers to examine respiration [40]. To our knowledge, this is the first report demonstrating that platelet respiration from a single mouse can be measured using the Seahorse XFe96 technology. Adequate resolution at low oxygen consumption rates (OCRs) allows as little as $10 \mu \mathrm{g}$ platelet protein (approximately $1 \times 10^{7}$ platelets) to be used in each well for oxygen consumption measurements [41].

Measurements of bioenergetics in platelets were completed using a Seahorse XFe96 Flux Analyzer (Agilent Technologies, Santa Clara, CA, USA). The OCR was measured in the presence of substrates, inhibitors, and uncouplers related to OXPHOS as modified from previously described methods $[42,43]$. The day before the planned experiment, the sensor cartridge of Extracellular Flux kit was filled with $200 \mu \mathrm{L}$ deionized water and kept at $37^{\circ} \mathrm{C}$ overnight. At least $30 \mathrm{~min}$ prior to use, the water was removed, the plate filled with $200 \mu \mathrm{L} \mathrm{XF}$ calibrant solution and put back at $37^{\circ} \mathrm{C}$. The injection ports, A to D of the sensor cartridge, were loaded separately or in combinations of substrates/inhibitors/uncouplers to measure different states of respiration. Before loading, the stocks were diluted appropriately in PPG buffer such that after each sequential injection, the final concentration of the modulators was $5 \mathrm{mM}$ pyruvate, $2.5 \mathrm{mM}$ malate, and $10 \mathrm{mM}$ succinate (via Port A), $5 \mu \mathrm{M}$ oligomycin A (via Port B), $4 \mu \mathrm{M}$ FCCP (via Port C), and $1 \mu \mathrm{M}$ antimycin A (via Port D). Either 10 or $30 \mu \mathrm{g}$ total platelet protein (approximately $1 \times 10^{7}$ or $3 \times 10^{7}$ platelets) was loaded per well on a Seahorse XFe96 assay plate in a total volume of $30 \mu \mathrm{l}$ (platelet sample plus PPG buffer). The assay plates were centrifuged at $2100 \times \mathrm{g}$ for $4 \mathrm{~min}$ at RT. Additional pre-warmed PPG buffer was added to bring the starting volume to $175 \mu \mathrm{L}$. After the calibration step, the utility plate was replaced by the assay plate carrying platelet samples. Seahorse Standard XFe96 flux assay plates were utilized for platelet analysis. Oxygen consumption rates (OCR) and extra-cellular acidification rate (ECAR) were recorded in the absence or the presence of various substrates/inhibitors which were added from port A 
to port D. These measurements were performed on intact (non-permeabilized) platelets. Basal readings were performed in the presence of glucose in the buffer. OXPHOS, LEAK, MAX, and non-mitochondrial (NON-MITO) oxygen consumption respiration rates were recorded based on subsequent port injections (Figure 1). Basal glycolysis was measured as ECAR in the presence of glucose without substrate addition. Maximum glycolysis was measured as ECAR after the addition of oligomycin according to the injection paradigm in Figure 1. Platelet coupling efficiency was calculated by OXPHOS/LEAK, while glycolytic reserve capacity was calculated by Max glycolysis-Basal glycolysis. Raw OCR and ECAR values were used for analysis within a given experiment and reported in all figures.

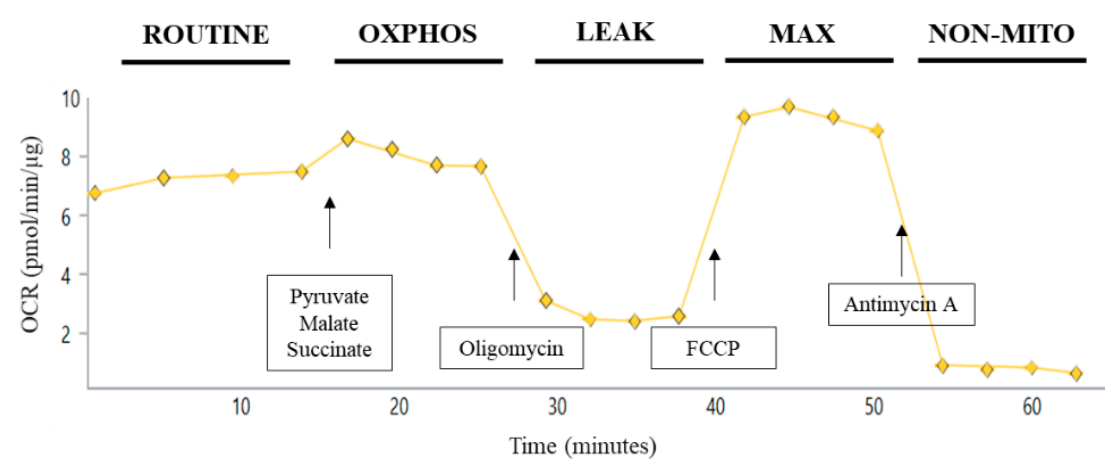

Figure 1. Substrate/inhibitor injection protocol for Seahorse assay of intact platelets. Utilizing the Seahorse XFe96 Flux Analyzer enables the assessment of up to 30 independent samples in triplicate at one time. For respirometry of intact platelets, platelets were added in prostacyclin/phosphate/glucose buffer; this state of respiration is defined as ROUTINE. For injection A, $5 \mathrm{mM}$ pyruvate, $2.5 \mathrm{mM}$ malate, and $10 \mathrm{mM}$ succinate were added to give OXPHOS $_{\mathrm{CI}+\mathrm{CII}}$ of platelets. Oligomycin $(5 \mu \mathrm{M})$ was injected next to give LEAK platelet respiration. FCCP $(4 \mu \mathrm{M})$ was then added in injection $\mathrm{C}$ for $\mathrm{MAX}_{\mathrm{CI}+\mathrm{CII}}$. Finally, non-mitochondrial (NON-MITO) oxygen consumption, independent of the electron transport system, is measured after addition of antimycin A $(1 \mu \mathrm{m})$.

\subsection{Statistical Analysis}

Power analysis was conducted for experimental data a priori based on an effect size and expected data variance. Statistical analysis was performed using Graph Pad Prism 8 (GraphPad Software, San Diego, CA, USA) or JMP Pro 14 (SAS, Cary, NC, USA). For all analyses, the significance of differences among groups was set at $p<0.05$. For each measure, data were measured using interval/ratio scales. The Brown-Forsythe and Bartlett's tests were performed to ensure homogeneity of variance. Furthermore, the Shapiro-Wilk test was completed to ensure normality. As these criteria were met for all experimental data, parametric statistics were employed for all analyses. For data obtained on PNAs, a statistical blocking factor for assay day was utilized to reduce within group variability between assays runs. For platelet bioenergetics data, raw OCR/ECAR values were used for analysis within a given experiment. For all analyses, unpaired two-tailed t-test was performed to compare sham and injured groups.

\section{Results}

\subsection{Does Not Change Platelet Parameters But Decreases Early Blood Leukocyte Levels}

To assess the acute effects on peripheral blood cell profiles following CCI, we examined hematological parameters at 6 and $24 \mathrm{~h}$ post-injury. There were no significant differences, either at 6 or $24 \mathrm{~h}$, for RBC counts (Figure 2). Leukocyte counts were significantly decreased at $6 \mathrm{~h}$ post-CCI compared to sham (Figure 2). Systemic leukocyte counts were restored by $24 \mathrm{~h}$ post-injury. There were also no changes in platelet counts or mean platelet volume (MPV) early after CCI. 


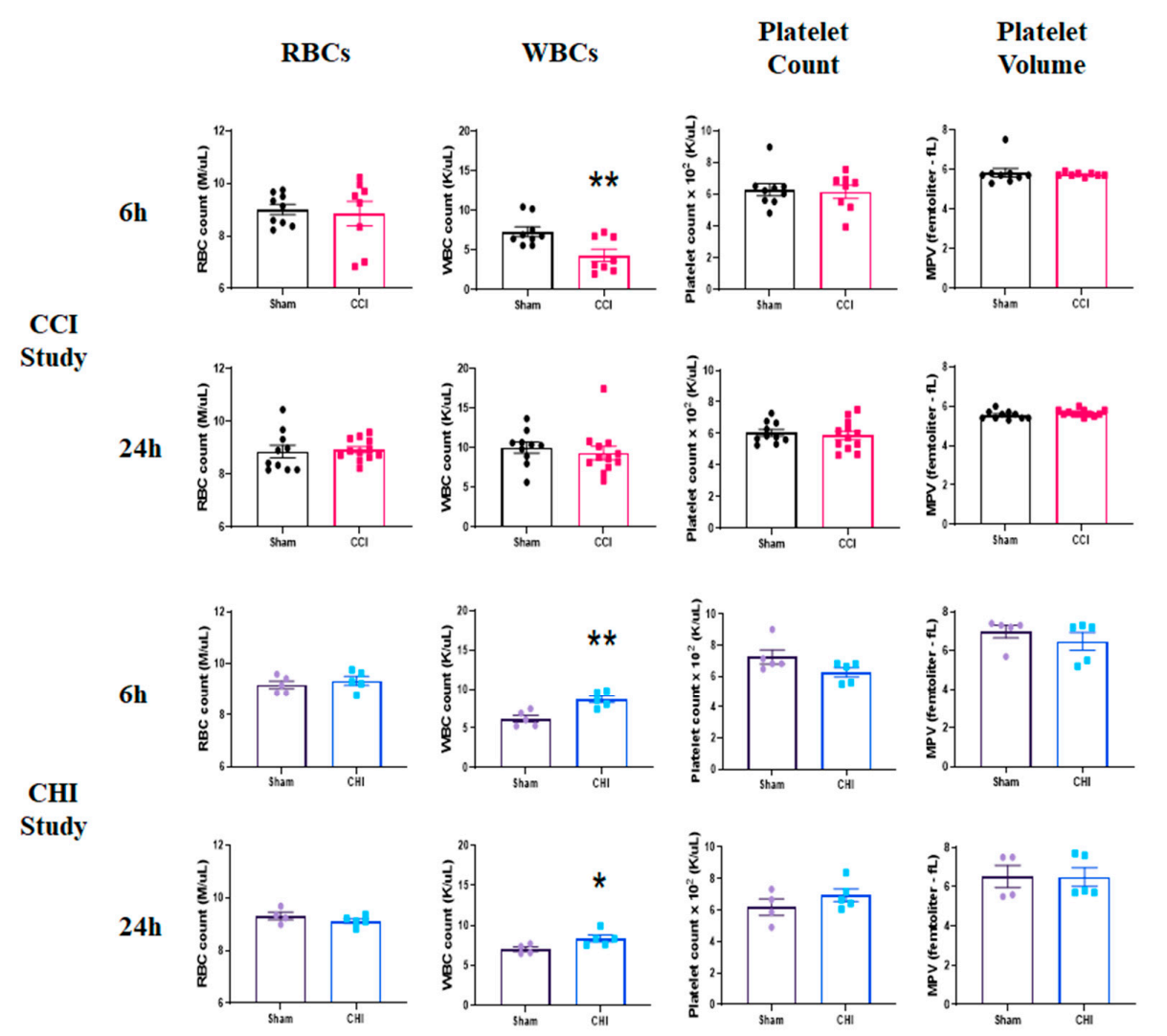

Figure 2. Early profile of blood cell alterations following contusion brain injury (CCI) and mild closed head impact (CHI). (Top Panels) Mice received either sham injury or severe CCI followed by euthanasia at either 6 or 24 h post-injury. Examination of RBC counts, WBC counts, platelet counts, and mean platelet volume (MPV) was performed by an IDEXX ProCyte Dx Analyzer. CCI does not alter RBC counts, platelet counts, or platelet volume at 6 or $24 \mathrm{~h}$ after injury. However, WBCs were significantly decreased after CCI compared to sham at $6 \mathrm{~h}$ post-injury before restoration at $24 \mathrm{~h}$ post-injury. ${ }^{* *} p=0.0076 ; \mathrm{t}=3.083 . \mathrm{n}=8-9$ /group. (Bottom Panels) Mice received either sham injury or mild CHI followed by euthanasia at either 6 or 24 h post-injury. Examination of RBC counts, WBC counts, platelet counts, and mean platelet volume (MPV) was performed. CHI does not significantly change RBC counts, platelet counts, or platelet volume at 6 or $24 \mathrm{~h}$ after injury. However, WBCs were significantly increased after CHI compared to sham at both 6 and 24 h post-injury. ${ }^{* *} p=0.0039$; $\mathrm{t}=4.009$. ${ }^{*} p=0.048 ; \mathrm{t}=2.397$. $\mathrm{n}=4-5$ /group. Mean \pm SEM.

\subsection{CHI Does Not Alter Platelet Parameters But Rather Increases Blood Leukocyte Levels}

Similar to our previous reports [37], a single CHI resulted in an immediate apnea response $(17.2 \pm 3.0 \mathrm{~s})$ and an increase in time to right after a 10-minute sustained bout of anesthesia (CHI: $5.0 \pm 1.3 \mathrm{~min}$ vs. Sham: $1.3 \pm 0.1 \mathrm{~min}$ ). RBC counts were unchanged early after $\mathrm{CHI}$ (Figure 2). However, we found significantly higher leukocytes counts in the blood following $\mathrm{CHI}$ at both 6 and $24 \mathrm{~h}$ post-injury, compared to sham. This may be an indication of a delayed immune response in the brain or leukocytosis induced by diffuse mild TBI. We show that platelet counts and MPV are not changed at either 6 or $24 \mathrm{~h}$ following $\mathrm{CHI}$.

\subsection{Causes a Dynamic Shift in Early Platelet-Neutrophil Aggregation}

Platelet-leukocyte aggregates are indicative of the thromboinflammatory response following cerebral trauma [44]. Platelet-neutrophil aggregates (PNAs) represent the vast majority of platelet-leukocyte aggregates; as such, PNAs have been shown to increase following acute ischemic stroke [45]. Although we find that PNA levels are not significantly different at either 6 or $24 \mathrm{~h}$ after CCI compared to sham, the change in PNAs between these early time points was significantly different between sham and CCI (Figure 3). 


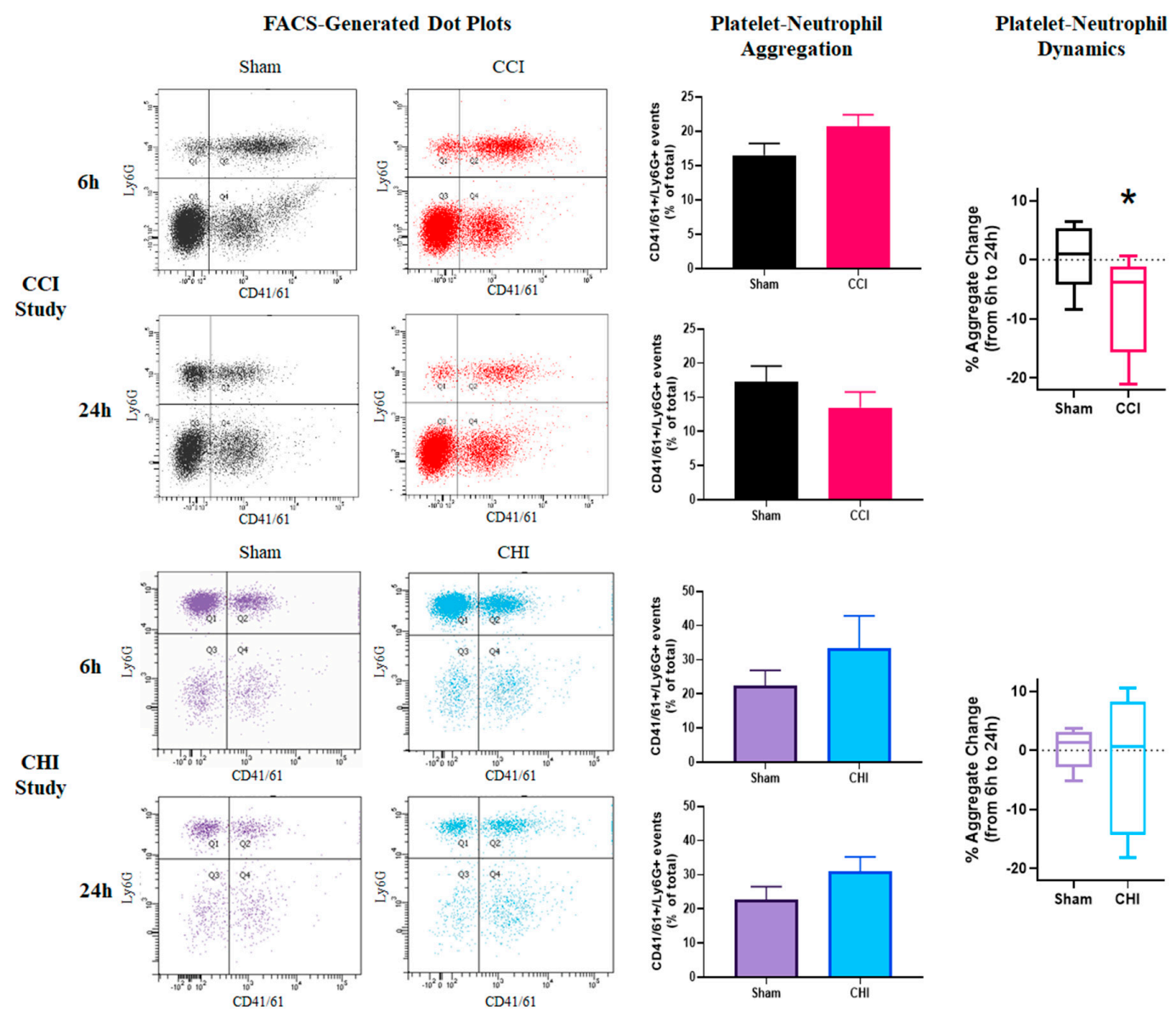

Figure 3. Divergent early profiles of platelet-neutrophil aggregation after contusion brain injury and mild closed head impact. (Top Panels) Mice received either sham injury or severe CCI followed by euthanasia at either 6 or 24 h post-injury. FACS analysis was performed on blood samples to examine platelet-neutrophil aggregation. Representative dot plots of flow cytometry showing platelet-neutrophil aggregates (PNAs) in the top-right quadrant of each plot. There were no significant differences in PNAs after CCI at either 6 or $24 \mathrm{~h}$ post-injury when compared to time-matched sham controls. There was a significant difference between sham and CCI groups in platelet-neutrophil dynamics (relative change of PNAs) from 6 to $24 \mathrm{~h}$ post-injury. ${ }^{*} p=0.032 . \mathrm{t}=2.373 . \mathrm{n}=8-9$ /group. (Bottom Panels) Mice received either sham injury or mild $\mathrm{CHI}$ followed by euthanasia at either 6 or $24 \mathrm{~h}$ post-injury. FACS analysis was performed on blood samples to examine platelet-neutrophil aggregation. Representative dot plots of flow cytometry showing platelet-neutrophil aggregates (PNAs) in the top-right quadrant of each plot. Levels of platelet-neutrophil aggregates (PNAs) was slightly elevated, though not significantly different, in mice receiving $\mathrm{CHI}$ at both 6 and $24 \mathrm{~h}$ post-injury when compared to time-matched sham controls. There was no significant difference between sham and CHI groups in the platelet-neutrophil dynamics from 6 to $24 \mathrm{~h}$ post-injury. $n=5$ /group. Mean \pm SEM.

\subsection{CHI Does Not Alter Platelet-Neutrophil Aggregation Acutely After Injury}

Although at both 6 and $24 \mathrm{~h}$ the mean PNA levels were higher for the CHI group than the sham controls, this difference did not reach statistical significance (Figure 3). This slight increase may be indicative of an early thromboinflammatory response following CHI. There was no early shift in PNA levels between 6 and $24 \mathrm{~h}$ following CHI.

\subsection{Produces an Acute Shift in Platelet Coupling Efficiency}

Metabolic changes in platelets, which may relate to disease progression [23], can be readily assessed using respirometry techniques. Platelet respiratory parameters, such as coupling efficiency and reserve capacity, were similar to previously published results [42]. As stated previously, this is the first study, to our knowledge, that demonstrates the measurement of platelet respiration from a single mouse (versus pooled samples). There were no changes in any platelet respiration state at either 6 or $24 \mathrm{~h}$ following CCI (Figure 4). 
However, the coupling efficiency of platelets was lower at $6 \mathrm{~h}$ and higher at $24 \mathrm{~h}$ after CCI compared to sham (Figure 4). An expanded time course showed that coupling efficiency returned to sham levels at 12 and $18 \mathrm{~h}$ post-injury before an increase at $24 \mathrm{~h}$ following CCI (Figure S1), demonstrating a gradual transition acutely after CCI. The glycolytic signature of platelets was unchanged after CCI (Figure 4).
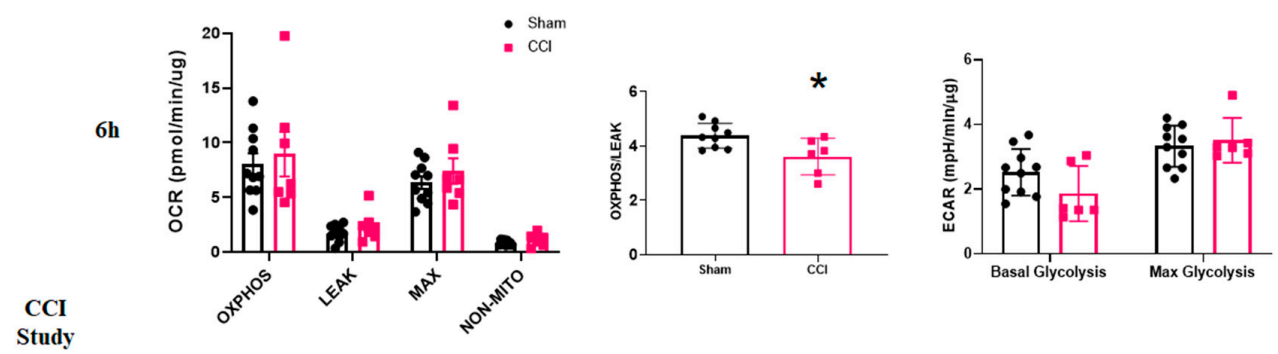

24h
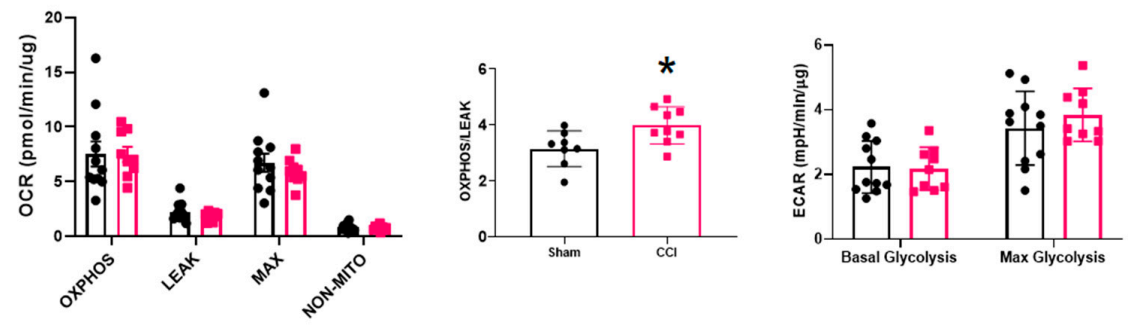

$6 \mathbf{h}$
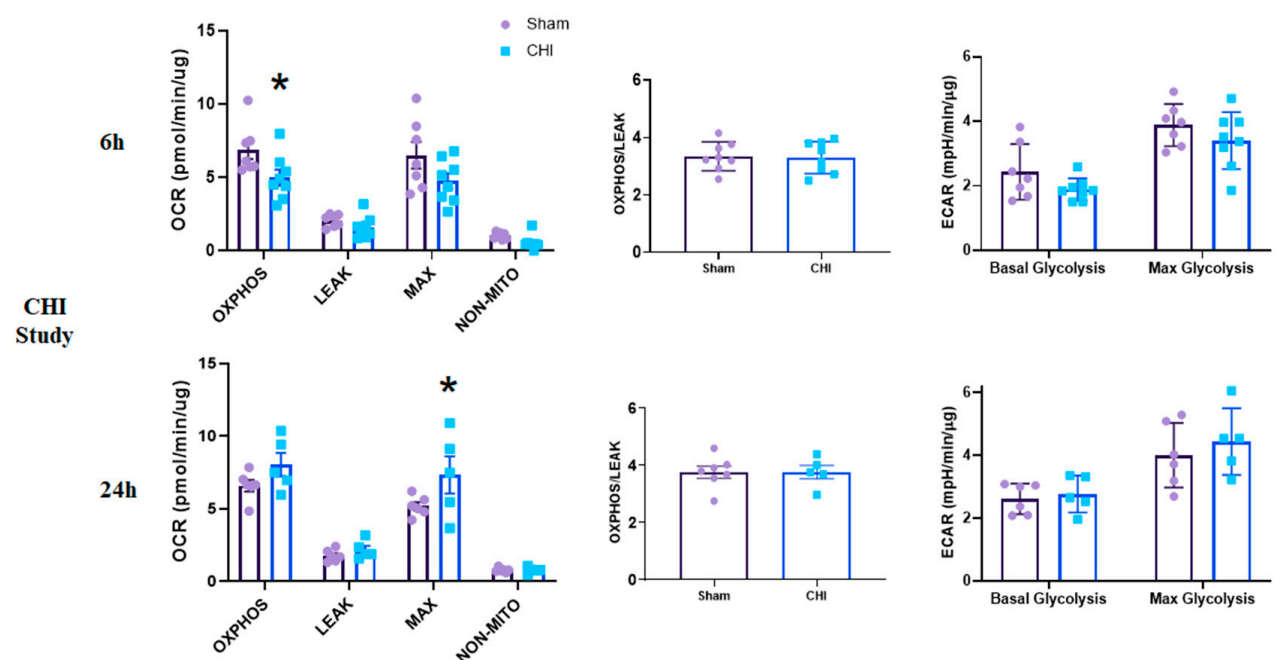

Figure 4. Differential alterations in platelet coupling and oxidative phosphorylation acutely following contusion brain injury and mild closed head injury. (Top Panels) Mice received either sham injury or severe CCI followed by euthanasia at either 6 or $24 \mathrm{~h}$ post-injury. Isolated platelets underwent respirometry using the Seahorse XFe96. At 6 or $24 \mathrm{~h}$ post-CCI, there were no significant differences in any state of respiration measured. Platelet coupling efficiency was reduced $6 \mathrm{~h}$ after CCI compared to sham. $\mathrm{t}=2.656 ;{ }^{*} p=0.012$. There was a significant increase in platelet coupling efficiency 24 $\mathrm{h}$ after CCI compared to sham. $\mathrm{t}=2.637 ;{ }^{*} p=0.019$. Platelet glycolysis was unchanged at 6 and $24 \mathrm{~h}$ after CCI. $\mathrm{n}=$ 6-10/group, (Bottom Panels) Mice received either sham injury or mild CHI followed by euthanasia at either 6 or $24 \mathrm{~h}$ post-injury. Isolated platelets underwent respirometry using the Seahorse XFe96. At $6 \mathrm{~h}$ post-CHI, OXPHOS $\mathrm{CI+CII}$ was significantly lower in the $\mathrm{CHI}$ group compared to sham. $\mathrm{t}=2.284 ;{ }^{*} p=0.040$. In general, overall platelet respiration was lower at $6 \mathrm{~h}$ after $\mathrm{CHI}$ compared to sham. At $24 \mathrm{~h}$, post-CHI, MAX $\mathrm{CI}+\mathrm{CII}$ was significantly higher in the $\mathrm{CHI}$ group compared to sham. $\mathrm{t}=3.12 ;{ }^{*} p=0.0142$. In general, overall platelet respiration was higher at $24 \mathrm{~h}$ after $\mathrm{CHI}$ compared to sham. Platelet coupling efficiency was unchanged at 6 and $24 \mathrm{~h}$ after CHI. There was no significant difference in platelet glycolysis at either 6 or $24 \mathrm{~h}$ following CHI. $\mathrm{n}=5-8$ /group. Mean \pm SEM. 


\subsection{CHI Causes Early Alterations in Platelet Bioenergetics after Injury}

After $\mathrm{CHI}$, platelets displayed lower OXPHOS levels at $6 \mathrm{~h}$ post-injury compared with sham (Figure 4). By $24 \mathrm{~h}$, however, platelets from mice with $\mathrm{CHI}$ exhibit significantly higher MAX respiration levels compared to those from sham mice (Figure 4). Neither platelet coupling efficiency nor platelet glycolysis (Figure 4) changed acutely after CHI.

\section{Discussion}

This study shows that early blood cell dynamics are differentially altered between experimental contusion TBI and mild diffuse TBI. The two distinct injury models used in this study represent differing injury severity, pathobiology, and spatial injury progression. The immune response following CNS injury is initiated by damage- and pathogen-associated molecular patterns (DAMPs/PAMPs), followed closely by neutrophil interactions in the brain [46]. The exact progression of leukocyte mobilization or brain infiltration is not clear, but we show in this study that these mechanisms are distinct between closed head impact and contusion brain injury. Waves of early leukocyte infiltration into the brain, including neutrophils (hours after injury) and monocytes/T lymphocytes (days after injury), are well-documented following CCI $[9,44,47]$. Comparatively, leukocyte infiltration is modest following CHI [10]. Our results show an early, transient decrease in leukocyte counts after CCI. We also demonstrate that blood leukocyte levels increase at both 6 and $24 \mathrm{~h}$ after CHI compared to sham. Clinically, blood leukocyte levels are increased early after TBI [48] and this increase is dependent, to some extent, on injury severity [47]. Elevated blood leukocyte levels, measured upon hospital admission, were identified as a prognostic biomarker for severe head injury by correlating with an unfavorable outcome at 6 months post-injury [49], though another study found no association with increased leukocyte counts and 6 month outcome [50]. Blood leukocyte levels measured following CCI do not align with these clinical findings. It has been shown that catecholamine released after TBI contributes to leukocytosis, including mobilization of marginal or adherent leukocytes [51,52]. CHI may induce leukocytosis, potentially via catecholamine release without early overt infiltration into the brain. The large increases that we observed in blood leukocyte population after $\mathrm{CHI}$ could be the physiologic mechanism for on-going or even delayed immune response in the injured brain and are clinically relevant. Longitudinal studies to expand upon the current results are needed.

Platelet-leukocyte interactions increase in environments of inflammation. It is wellknown that the influx of inflammatory blood cells occurs at the BBB after brain damage $[6,12]$ and this infiltration, which is propagated by the dysfunctional neurovascular unit, contributes to on-going neuroinflammation [53,54]. In the current study, we demonstrate how TBI can contribute to early systemic inflammation as well. Clinically, acute platelet-leukocyte aggregation increases have been correlated with neurological deterioration following ischemia [45]. Post-TBI microthrombi have been observed in the brain; indeed, platelet-leukocyte interactions have been shown to promote thrombosis following TBI [55]. We show a small, non-significant increase in PNA levels at $6 \mathrm{~h}$ after CCI with a significant decline from 6 to $24 \mathrm{~h}$ post-CCI. These acute PNA dynamics need further investigation to understand their role in pathophysiology following CCI. Following CHI, slight, though non-significant, increases in PNAs were observed acutely, which could be related to elevated leukocyte levels in the blood after CHI. Future studies with extended time course, and incorporation of repeated CHIs, are warranted to examine the temporal progression of PNAs after TBI. Furthermore, platelets have been shown to propagate monocyte differentiation into macrophages [56], so platelet interaction with monocyte/macrophage may also be important following TBI and, in turn, influence the bioenergetic status of platelets.

While neuroimaging techniques, including computed tomography (CT), MRI, diffusionweighted imaging, and diffusion tensor imaging, are commonly used for diagnosis and prognosis of TBI, these are not meant for point-of-care or longitudinal tracking. Serum and cerebrospinal fluid (CSF) markers also are routinely used for diagnosis and prognosis of TBI. As an alternative, platelets have been widely recognized to mirror the progression 
of neurological disease. As the pathobiology of TBI is dynamic, these biomarker-based measures are just a glimpse of a continually evolving disease state. While serum biomarkers may have complex kinetics (release from the brain, crossing the BBB, and systemic clearance), platelet function can be pathologically altered following interactions in the damaged brain. We present initial findings of platelet alteration after TBI, but additional research is needed. Indeed, future studies can be performed to monitor platelet function with FACS-based techniques (collected serially) correlated to behavioral and histological outcome as a "within subject" analysis. Additionally, RNA-seq could be employed to build off of this work enabling biomarker discovery in the blood transcriptome following TBI [57].

We show here that platelet counts and MPV are stable early after either CCI or CHI. Previous studies showed that platelet counts are unaltered at $6 \mathrm{~h}$ following weight-drop closed head impact [19]. Another study found no changes in platelet counts or MPV after closed head TBI in the rat within $1 \mathrm{~h}$ after injury [18]. Hypercoagulability occurs early following CHI, despite no alteration in platelet count [19]. Our results build upon these findings and further demonstrate that changes in platelet function or metabolism are independent of changes in platelet count or MPV.

To our knowledge, no study has been published on platelet bioenergetic changes after TBI. We show distinct temporal alterations in platelet respiration in a model of mild TBI at acute time points. It is known that platelet activation leads to increased oxidative phosphorylation [58]. For example, the addition of thrombin increases OXPHOS, while the addition of indomethacin inhibits platelet activity and decreases OXPHOS. After closed head injury, we show that platelet respiration increases at $24 \mathrm{~h}$, alluding to elevated platelet activation and potentially mechanisms of delayed thrombosis after CHI. Following contusion brain injury, platelet coupling efficiency is decreased at $6 \mathrm{~h}$ and increased at $24 \mathrm{~h}$ after CCI.

Platelets are uniquely suited to play a variety of roles following TBI. Platelets, measuring $\sim 1-3 \mu \mathrm{m}$, have the ability to circulate in a majority of the brain microvasculature, facilitating their critical role in vascular remodeling following injury [59,60]. As microvascular injury is a hallmark of TBI, there is high potential for enhanced platelet-brain cell communication in these compromised areas [5]. Platelets may play a major role in BBB dysfunction after TBI. In areas of BBB breakdown, the glycoprotein Ib-IX-V complex on the surface of platelets binds to von Willebrand factor (vWF) in the subendothelium [61]. The role of platelets goes well beyond that related to hemostasis following TBI; platelets interact with the BBB and cerebral parenchyma after injury. It was recently reported that platelet C-type lectin-like 2 (CLEC-2) receptors regulate the neuroinflammatory response and integrity of the BBB following TBI [62]. Platelets can communicate with neurons through release of microparticles, exosomes, and potentially neurogenic factors [63]. Another method of molecular communication is via damage-/pathogen-associated molecular patterns (DAMP/PAMPS) that are released following TBI and induce a platelet-mediated inflammatory response [64]. Platelet accumulation in regions of CNS damage helps promote neurogenesis and white matter repair [65].

It is interesting that decreased OXPHOS rates in platelets at $6 \mathrm{~h}$ precedes decreased State III bioenergetics in the cortex at $24 \mathrm{~h}$ in the CHI model [2]. Platelets may sense specific neuronal/glial populations near the vasculature to account for this discrepancy in metabolic changes. Previously, it has been reported that maximal respiration of cortical mitochondria from female green monkeys positively correlates with parameters of platelet respiration [29]. Our group has shown dysfunction in brain mitochondria early after both CCI and CHI [2,36]; further analysis will examine the correlation with platelet bioenergetics after experimental TBI. We observe that platelet coupling increases at $24 \mathrm{~h}$ after CCI, which coincides with decreased mitochondrial bioenergetics in the brain, as previously described [66]. This is consistent with acutely elevated platelet coupling efficiency corresponding with lower cerebral bioenergetics in a model of cardiac arrest [30]. 
Platelets are bioenergetically well-coupled compared to other blood cell types, demonstrating higher ATP-linked respiration (OXPHOS) and lower LEAK respiration [42]. Platelets are also more glycolytic compared to other blood cell types [42]. The lack of glycolytic alteration in this current study suggests that platelet bioenergetic changes are occurring at the mitochondrial level. Although no changes were seen in platelet glycolysis early after TBI, it would be important to examine whether the glycolytic response to a cellular challenge (e.g., agonists such as thrombin) is altered after TBI. It is plausible that platelets in TBI subjects could be predisposed to altered metabolic responses. Furthermore, mitochondrial dysfunction in platelets themselves could result in secondary coagulopathy, leading to increased risk of thrombosis through activation and microparticle secretion [67].

Shifts in platelet respiration early after injury could be, in part, due to platelet turnover. However, newly formed platelets may continue to interact with the dysfunctional BBB and demonstrate altered bioenergetics. Alternatively, mitochondrial respiration alterations in platelets could represent changes in the mitochondrial genome [68]. Although there is a lack of investigation regarding mtDNA changes in the context of TBI, platelets could be the ideal sensor to measure these changes.

We acknowledge several limitations of this study. First, only male mice were used in these assays. While in the absence of TBI, platelet respiration in humans does not significantly vary with sex [43], additional studies are needed to assess sex-specific responses in the context of TBI. Female animals should be included in future studies to fully encompass the systemic blood cell response to TBI relative to sex. Blood cell changes were only examined at 6 and $24 \mathrm{~h}$ after injury; future studies should examine whether platelet bioenergetics are altered chronically following TBI. While hematological analysis was able to uncover general changes in white blood cell populations after TBI, future studies are needed to perform FACS phenotyping analysis to examine alterations in specific subsets of leukocytes in both whole blood and the spleen after CCI and CHI. There are also limitations to the examination of respiration in intact platelets. Succinate, which has limited cellular uptake, is given to the intact platelets in this study, so it is difficult to know the affect succinate has on platelet respiration [69]. Future studies should examine whether cell permeabilization with direct, unhindered access to mitochondria [43] produces any further insight into TBI-induced alteration of platelet mitochondrial bioenergetics.

In this study, prostacyclin, which inhibits platelet activation and aggregation, was in the buffer during the Seahorse experiments. Therefore, the results are indicative of platelet bioenergetic changes in an inactivated state with potentially altered glucose metabolism. Future studies, incorporating a wash of prostacyclin before respirometry measurements, should be performed. Moreover, platelet function may be altered after TBI with the addition of an activating stimuli, such as ADP or thrombin [70]. Platelets do not have a high reserve respiratory capacity, especially when compared to other blood cells, such as monocytes or lymphocytes [42,43]. Here, we show no significant differences between OXPHOS and MAX levels within our experimental groups. However, Sjovall et al. showed that MAX rates are significantly lower with the addition of oligomycin compared to those without oligomycin [43]. This highlights a potential limitation of the present study, though it is difficult to compare between different respirometry devices.

\section{Conclusions}

Our findings indicate that CCI produces early blood cell alterations, including low blood leukocyte levels, dynamic PNA interactions, and alterations in metabolic coupling in platelets. CHI, however, appears to produce thromboinflammatory effects with high acute levels of blood leukocytes, slightly elevated PNAs, and delayed increases in platelet bioenergetics. These mechanisms, related to thromboinflammation, require further exploration, though current results highlight clinically-relevant outcomes following CHI. Finally, we posit that platelet bioenergetics may have diagnostic and prognostic value, related to cerebral metabolism, to peripherally monitor progression of TBI. 
Supplementary Materials: The following are available online at https: / /www.mdpi.com/2073-4 409/10/3/500/s1, Figure S1: Dynamic changes in platelet coupling efficiency acutely following contusion brain injury, Figure S2: Schematic for platelet-neutrophil aggregates in whole mouse blood.

Author Contributions: Conceptualization, W.B.H., S.W.W., and P.G.S.; methodology, W.B.H., K.E.S., S.W.W., and P.G.S.; validation, W.B.H.; formal analysis, W.B.H. and M.B.; investigation, W.B.H., M.B., H.V., K.S.P., S.J., and Q.J.W.; writing—original draft preparation, W.B.H.; writing-review and editing, W.B.H., M.B., Q.J.W., K.E.S., S.W.W., and P.G.S.; visualization, W.B.H.; supervision, P.G.S.; funding acquisition, W.B.H., Q.J.W., K.E.S., S.W.W., and P.G.S. All authors have read and agreed to the published version of the manuscript.

Funding: This research was funded by a VA Merit Award 1I01BX003405-01A1 (to P.G.S.), a VA Merit Award (to S.W.W.), and a Career Development Award, Number IK2 BX004618-01A1 (to W.B.H) from the United States Department of Veterans Affairs Biomedical Laboratory Research and Development Program. The contents do not represent the views of the U.S. Department of Veterans Affairs or the United States Government. The work was also supported by NIH R01 NS112693-01A1 (to P.G.S.), NIH R21 NS114771-01A1 (to K.E.S.), NIH grants HL56652, HL138179, and HL150818 (to S.W.W.), the Kentucky Spinal Cord and Head Injury Research Trust (KSCHIRT) Grant 14-13A and 15-14A, and the American Heart Association grant AHA16GRNT31310020 (to Q.J.W.).

Institutional Review Board Statement: The study was conducted according to the guidelines of Association for the Assessment and Accreditation for Laboratory Animal Care, International and approved by the University of Kentucky Institutional Animal Care and Use Committee (IACUC) (protocol code 2012-1005; mitoNEET as a Therapeutic Target of Pioglitazone following TBI (approved 09/19/2018); protocol code 2018-3076; Innovative tools for mapping cerebral blood flow and mitochondrial responses to repeated mild TBI (approved 09/24/2018)). All animal experiments complied with ARRIVE (Animal Research: Reporting of In Vivo Experiments) guidelines and experiments were carried out in accordance with the National Institutes of Health Guide for the Care and Use of Laboratory Animals (NIH Publications No. 8023, 8th edition, revised 2011).

Informed Consent Statement: Not applicable.

Data Availability Statement: The data presented in this study are available on request from the corresponding author.

Acknowledgments: We would like to thank Malinda Spry, Jenn Gooch, and Binoy Joseph, PhD for their assistance in the experimental TBI models. We would also like to thank the services and equipment provided by Greg Bauman and the Flow Cytometry and Immune Monitoring Core Facility at the University of Kentucky.

Conflicts of Interest: The authors declare no conflict of interest. The funders had no role in the design of the study; in the collection, analyses, or interpretation of data; in the writing of the manuscript, or in the decision to publish the results.

\section{References}

1. Lyons, D.N.; Vekaria, H.; Macheda, T.; Bakshi, V.; Powell, D.K.; Gold, B.T.; Lin, A.L.; Sullivan, P.G.; Bachstetter, A.D. A Mild Traumatic Brain Injury in Mice Produces Lasting Deficits in Brain Metabolism. J. Neurotrauma 2018, 35, 2435-2447. [CrossRef]

2. Hubbard, W.B.; Joseph, B.; Spry, M.; Vekaria, H.J.; Saatman, K.E.; Sullivan, P.G. Acute Mitochondrial Impairment Underlies Prolonged Cellular Dysfunction after Repeated Mild Traumatic Brain Injuries. J. Neurotrauma 2019, 36, 1252-1263. [CrossRef]

3. Hubbard, W.B.; Davis, L.M.; Sullivan, P.G. Mitochondrial Damage in Traumatic CNS Injury. In Acute Neuronal Injury: The Role of Excitotoxic Programmed Cell Death Mechanisms; Fujikawa, D.G., Ed.; Springer International Publishing: Cham, Germany, 2018; pp. 63-81. [CrossRef]

4. Hubbard, W.B.; Vekaria, H.J.; Sullivan, P.G. Chapter 17-Mitochondrial drug delivery systems: Therapeutic application for clinical bioenergetics in neurodegenerative disease. In Clinical Bioenergetics; Ostojic, S., Ed.; Academic Press: Cambridge, MA, USA, 2021; pp. 385-409. [CrossRef]

5. Sandsmark, D.K.; Bashir, A.; Wellington, C.L.; Diaz-Arrastia, R. Cerebral Microvascular Injury: A Potentially Treatable Endophenotype of Traumatic Brain Injury-Induced Neurodegeneration. Neuron 2019, 103, 367-379. [CrossRef]

6. Chodobski, A.; Zink, B.J.; Szmydynger-Chodobska, J. Blood-brain barrier pathophysiology in traumatic brain injury. Transl. Stroke Res. 2011, 2, 492-516. [CrossRef]

7. Hubbard, W.B.; Lashof-Sullivan, M.; Greenberg, S.; Norris, C.; Eck, J.; Lavik, E.; VandeVord, P. Hemostatic nanoparticles increase survival, mitigate neuropathology and alleviate anxiety in a rodent blast trauma model. Sci. Rep. 2018, 8, 10622. [CrossRef] 
8. Nag, S.; Kapadia, A.; Stewart, D.J. Review: Molecular pathogenesis of blood-brain barrier breakdown in acute brain injury. Neuropathol. Appl. Neurobiol. 2011, 37, 3-23. [CrossRef] [PubMed]

9. Schwarzmaier, S.M.; Zimmermann, R.; McGarry, N.B.; Trabold, R.; Kim, S.-W.; Plesnila, N. In vivo temporal and spatial profile of leukocyte adhesion and migration after experimental traumatic brain injury in mice. J. Neuroinflamm. 2013, 10, 808. [CrossRef]

10. Chung, J.Y.; Krapp, N.; Wu, L.; Lule, S.; McAllister, L.M.; Edmiston, W.J., 3rd; Martin, S.; Levy, E.; Songtachalert, T.; Sherwood, J.S.; et al. Interleukin-1 Receptor 1 Deletion in Focal and Diffuse Experimental Traumatic Brain Injury in Mice. J. Neurotrauma 2019, 36, 370-379. [CrossRef]

11. Leiter, O.; Walker, T.L. Platelets in Neurodegenerative Conditions-Friend or Foe? Front. Immunol. 2020, 11, 747. [CrossRef]

12. Hubbard, W.B.; Dong, J.F.; Cruz, M.A.; Rumbaut, R.E. Links between thrombosis and inflammation in traumatic brain injury. Thromb. Res. 2020, 198, 62-71. [CrossRef]

13. Davis, P.K.; Musunuru, H.; Walsh, M.; Cassady, R.; Yount, R.; Losiniecki, A.; Moore, E.E.; Wohlauer, M.V.; Howard, J.; Ploplis, V.A.; et al. Platelet dysfunction is an early marker for traumatic brain injury-induced coagulopathy. Neurocrit. Care 2013, 18, 201-208. [CrossRef]

14. Nekludov, M.; Bellander, B.M.; Blombäck, M.; Wallen, H.N. Platelet dysfunction in patients with severe traumatic brain injury. J. Neurotrauma 2007, 24, 1699-1706. [CrossRef]

15. Guillotte, A.R.; Herbert, J.P.; Madsen, R.; Hammer, R.D.; Litofsky, N.S. Effects of platelet dysfunction and platelet transfusion on outcomes in traumatic brain injury patients. Brain Inj. 2018, 32, 1849-1857. [CrossRef] [PubMed]

16. Lindblad, C.; Thelin, E.P.; Nekludov, M.; Frostell, A.; Nelson, D.W.; Svensson, M.; Bellander, B.-M. Assessment of Platelet Function in Traumatic Brain Injury-A Retrospective Observational Study in the Neuro-Critical Care Setting. Front. Neurol. $2018,9,15$. [CrossRef]

17. Laroche, M.; Kutcher, M.E.; Huang, M.C.; Cohen, M.J.; Manley, G.T. Coagulopathy After Traumatic Brain Injury. Neurosurgery 2012, 70, 1334-1345. [CrossRef]

18. Donahue, D.L.; Beck, J.; Fritz, B.; Davis, P.; Sandoval-Cooper, M.J.; Thomas, S.G.; Yount, R.A.; Walsh, M.; Ploplis, V.A.; Castellino, F.J. Early platelet dysfunction in a rodent model of blunt traumatic brain injury reflects the acute traumatic coagulopathy found in humans. J. Neurotrauma 2014, 31, 404-410. [CrossRef]

19. Martin, G.E.; Xia, B.; Kim, Y.; Johnson, M.D.; Veile, R.; Friend, L.A.; Makley, A.T.; Caldwell, C.C.; Goodman, M.D. Platelet Function Changes in a Time-Dependent Manner Following Traumatic Brain Injury in a Murine Model. Shock 2018, 50, 551-556. [CrossRef]

20. Ploplis, V.A.; Donahue, D.L.; Sandoval-Cooper, M.J.; MorenoCaffaro, M.; Sheets, P.; Thomas, S.G.; Walsh, M.; Castellino, F.J. Systemic platelet dysfunction is the result of local dysregulated coagulation and platelet activation in the brain in a rat model of isolated traumatic brain injury. J. Neurotrauma 2014, 31, 1672-1675. [CrossRef]

21. Martin, G.E.; Pugh, A.M.; Moran, R.; Veile, R.; Friend, L.A.; Pritts, T.A.; Makley, A.T.; Caldwell, C.C.; Goodman, M.D. Microvesicles generated following traumatic brain injury induce platelet dysfunction via adenosine diphosphate receptor. J. Trauma Acute Care Surg. 2019, 86, 592-600. [CrossRef] [PubMed]

22. Wu, Y.; Liu, W.; Zhou, Y.; Hilton, T.; Zhao, Z.; Liu, W.; Wang, M.; Yeon, J.; Houck, K.; Thiagarajan, P.; et al. von Willebrand factor enhances microvesicle-induced vascular leakage and coagulopathy in mice with traumatic brain injury. Blood 2018, 132, 1075-1084. [CrossRef]

23. Petrus, A.T.; Lighezan, D.L.; Danila, M.D.; Duicu, O.M.; Sturza, A.; Muntean, D.M.; Ionita, I. Assessment of platelet respiration as emerging biomarker of disease. Physiol. Res. 2019, 68, 347-363. [CrossRef]

24. Zharikov, S.; Shiva, S. Platelet mitochondrial function: From regulation of thrombosis to biomarker of disease. Biochem. Soc. Trans. 2013, 41, 118-123. [CrossRef] [PubMed]

25. Parker, W.D., Jr.; Boyson, S.J.; Parks, J.K. Abnormalities of the electron transport chain in idiopathic Parkinson's disease. Ann. Neurol. 1989, 26, 719-723. [CrossRef]

26. Fišar, Z.; Hroudová, J.; Hansíková, H.; Spáčilová, J.; Lelková, P.; Wenchich, L.; Jirák, R.; Zvěřová, M.; Zeman, J.; Martásek, P.; et al. Mitochondrial Respiration in the Platelets of Patients with Alzheimer's Disease. Curr. Alzheimer Res. 2016, 13, 930-941. [CrossRef] [PubMed]

27. Mancuso, M.; Filosto, M.; Bosetti, F.; Ceravolo, R.; Rocchi, A.; Tognoni, G.; Manca, M.L.; Solaini, G.; Siciliano, G.; Murri, L. Decreased platelet cytochrome c oxidase activity is accompanied by increased blood lactate concentration during exercise in patients with Alzheimer disease. Exp. Neurol. 2003, 182, 421-426. [CrossRef]

28. Tyrrell, D.J.; Bharadwaj, M.S.; Jorgensen, M.J.; Register, T.C.; Molina, A.J. Blood cell respirometry is associated with skeletal and cardiac muscle bioenergetics: Implications for a minimally invasive biomarker of mitochondrial health. Redox Biol. 2016, 10, 65-77. [CrossRef]

29. Tyrrell, D.J.; Bharadwaj, M.S.; Jorgensen, M.J.; Register, T.C.; Shively, C.; Andrews, R.N.; Neth, B.; Dirk Keene, C.; Mintz, A.; Craft, S.; et al. Blood-Based Bioenergetic Profiling Reflects Differences in Brain Bioenergetics and Metabolism. Oxidative Med. Cell. Longev. 2017, 2017, 7317251. [CrossRef] [PubMed]

30. Ferguson, M.A.; Sutton, R.M.; Karlsson, M.; Sjövall, F.; Becker, L.B.; Berg, R.A.; Margulies, S.S.; Kilbaugh, T.J. Increased platelet mitochondrial respiration after cardiac arrest and resuscitation as a potential peripheral biosignature of cerebral bioenergetic dysfunction. J. Bioenerg. Biomembr. 2016, 48, 269-279. [CrossRef] 
31. Saatman, K.E.; Duhaime, A.C.; Bullock, R.; Maas, A.I.; Valadka, A.; Manley, G.T.; Workshop Scientific, T.; Advisory Panel, M. Classification of traumatic brain injury for targeted therapies. J. Neurotrauma 2008, 25, 719-738. [CrossRef] [PubMed]

32. Bolton-Hall, A.N.; Hubbard, W.B.; Saatman, K.E. Experimental Designs for Repeated Mild Traumatic Brain Injury: Challenges and Considerations. J. Neurotrauma 2019, 36, 1203-1221. [CrossRef] [PubMed]

33. McLeod, T.C.V.; Lewis, J.H.; Whelihan, K.; Bacon, C.E.W. Rest and Return to Activity After Sport-Related Concussion: A Systematic Review of the Literature. J. Athl. Train. 2017, 52, 262-287. [CrossRef]

34. Vagnozzi, R.; Signoretti, S.; Tavazzi, B.; Floris, R.; Ludovici, A.; Marziali, S.; Tarascio, G.; Amorini, A.M.; Di Pietro, V.; Delfini, R.; et al. Temporal window of metabolic brain vulnerability to concussion: A pilot $1 \mathrm{H}$-magnetic resonance spectroscopic study in concussed athletes-part III. Neurosurgery 2008, 62, 1286-1295, discussion 1295-1286. [CrossRef]

35. Vekaria, H.J.; Hubbard, W.B.; Scholpa, N.E.; Spry, M.L.; Gooch, J.L.; Prince, S.J.; Schnellmann, R.G.; Sullivan, P.G. Formoterol, a $\beta(2)$-adrenoreceptor agonist, induces mitochondrial biogenesis and promotes cognitive recovery after traumatic brain injury. Neurobiol. Dis. 2020, 140, 104866. [CrossRef] [PubMed]

36. Hubbard, W.B.; Harwood, C.L.; Geisler, J.G.; Vekaria, H.J.; Sullivan, P.G. Mitochondrial uncoupling prodrug improves tissue sparing, cognitive outcome, and mitochondrial bioenergetics after traumatic brain injury in male mice. J. Neurosci. Res. 2018, 96, 1677-1688. [CrossRef]

37. Bolton, A.N.; Saatman, K.E. Regional neurodegeneration and gliosis are amplified by mild traumatic brain injury repeated at 24-hour intervals. J. Neuropathol. Exp. Neurol. 2014, 73, 933-947. [CrossRef]

38. Pleasant, J.M.; Carlson, S.W.; Mao, H.; Scheff, S.W.; Yang, K.H.; Saatman, K.E. Rate of neurodegeneration in the mouse controlled cortical impact model is influenced by impactor tip shape: Implications for mechanistic and therapeutic studies. J. Neurotrauma 2011, 28, 2245-2262. [CrossRef]

39. Hubbard, W.B.; Harwood, C.L.; Prajapati, P.; Springer, J.E.; Saatman, K.E.; Sullivan, P.G. Fractionated mitochondrial magnetic separation for isolation of synaptic mitochondria from brain tissue. Sci. Rep. 2019, 9, 9656. [CrossRef]

40. Nayak, M.K.; Dhanesha, N.; Doddapattar, P.; Rodriguez, O.; Sonkar, V.K.; Dayal, S.; Chauhan, A.K. Dichloroacetate, an inhibitor of pyruvate dehydrogenase kinases, inhibits platelet aggregation and arterial thrombosis. Blood Adv. 2018, 2, 2029-2038. [CrossRef] [PubMed]

41. Ravi, S.; Chacko, B.; Kramer, P.A.; Sawada, H.; Johnson, M.S.; Zhi, D.; Marques, M.B.; Darley-Usmar, V.M. Defining the effects of storage on platelet bioenergetics: The role of increased proton leak. Biochim Biophys Acta 2015, 1852, 2525-2534. [CrossRef]

42. Chacko, B.K.; Kramer, P.A.; Ravi, S.; Johnson, M.S.; Hardy, R.W.; Ballinger, S.W.; Darley-Usmar, V.M. Methods for defining distinct bioenergetic profiles in platelets, lymphocytes, monocytes, and neutrophils, and the oxidative burst from human blood. Lab. Investig. 2013, 93, 690-700. [CrossRef] [PubMed]

43. Sjövall, F.; Ehinger, J.K.; Marelsson, S.E.; Morota, S.; Frostner, E.A.; Uchino, H.; Lundgren, J.; Arnbjörnsson, E.; Hansson, M.J.; Fellman, V.; et al. Mitochondrial respiration in human viable platelets-methodology and influence of gender, age and storage. Mitochondrion 2013, 13, 7-14. [CrossRef] [PubMed]

44. Finsterbusch, M.; Schrottmaier, W.C.; Kral-Pointner, J.B.; Salzmann, M.; Assinger, A. Measuring and interpreting platelet-leukocyte aggregates. Platelets 2018, 29,677-685. [CrossRef]

45. Htun, P.; Fateh-Moghadam, S.; Tomandl, B.; Handschu, R.; Klinger, K.; Stellos, K.; Garlichs, C.; Daniel, W.; Gawaz, M. Course of Platelet Activation and Platelet-Leukocyte Interaction in Cerebrovascular Ischemia. Stroke 2006, 37, 2283-2287. [CrossRef]

46. Jassam, Y.N.; Izzy, S.; Whalen, M.; McGavern, D.B.; El Khoury, J. Neuroimmunology of Traumatic Brain Injury: Time for a Paradigm Shift. Neuron 2017, 95, 1246-1265. [CrossRef]

47. Huang, X.; Dai, Y.; Ma, X.; Wang, S.; Xu, X.; Pei, X.; Li, R.; Wang, H. Different changes in granulocyte-colony stimulating factor and its correlation with inflammatory biomarkers in patients after traumatic brain injury. NeuroReport 2020, 31. [CrossRef] [PubMed]

48. Hassan, S.A.; Gassoum, A.; Aldeaf, S.A.H.; Arbab, M.A.R.; Musa, H.H. Association Between Acute Inflammatory Cells and Mutation in ICAM-1 Gene With Injury Severity and Outcome Among Traumatic Cerebral Hemorrhagic Contusion. J. Acute Med. 2020, 10, 1-8. [CrossRef] [PubMed]

49. Rovlias, A.; Kotsou, S. The blood leukocyte count and its prognostic significance in severe head injury. Surg. Neurol. 2001, 55, 190-196. [CrossRef]

50. Li, Z.; Wu, X.; Wu, X.; Yu, J.; Yuan, Q.; Du, Z.; Hu, J. Admission circulating monocytes level is an independent predictor of outcome in traumatic brain injury. Brain Inj. 2018, 32, 515-522. [CrossRef] [PubMed]

51. Benschop, R.J.; Rodriguez-Feuerhahn, M.; Schedlowski, M. Catecholamine-induced leukocytosis: Early observations, current research, and future directions. Brain Behav. Immun. 1996, 10, 77-91. [CrossRef]

52. Rizoli, S.B.; Jaja, B.N.R.; Di Battista, A.P.; Rhind, S.G.; Neto, A.C.; da Costa, L.; Inaba, K.; da Luz, L.T.; Nascimento, B.; Perez, A.; et al. Catecholamines as outcome markers in isolated traumatic brain injury: The COMA-TBI study. Crit. Care 2017, 21, 37. [CrossRef]

53. Zhou, Y.; Chen, Q.; Wang, Y.; Wu, H.; Xu, W.; Pan, Y.; Gao, S.; Dong, X.; Zhang, J.H.; Shao, A. Persistent Neurovascular Unit Dysfunction: Pathophysiological Substrate and Trigger for Late-Onset Neurodegeneration After Traumatic Brain Injury. Front. Neurosci. 2020, 14. [CrossRef] [PubMed]

54. Pop, V.; Badaut, J. A neurovascular perspective for long-term changes after brain trauma. Transl. Stroke Res. 2011, 2, 533-545. [CrossRef] [PubMed] 
55. Zhang, J.; Jiang, R.; Liu, L.; Watkins, T.; Zhang, F.; Dong, J.F. Traumatic brain injury-associated coagulopathy. J. Neurotrauma 2012, 29, 2597-2605. [CrossRef]

56. Kral, J.B.; Schrottmaier, W.C.; Salzmann, M.; Assinger, A. Platelet Interaction with Innate Immune Cells. Transfus. Med. Hemother. 2016, 43, 78-88. [CrossRef]

57. Bowyer, J.F.; Tranter, K.M.; Hanig, J.P.; Crabtree, N.M.; Schleimer, R.P.; George, N.I. Evaluating the Stability of RNA-Seq Transcriptome Profiles and Drug-Induced Immune-Related Expression Changes in Whole Blood. PLoS ONE 2015, 10, e0133315. [CrossRef] [PubMed]

58. Aibibula, M.; Naseem, K.M.; Sturmey, R.G. Glucose metabolism and metabolic flexibility in blood platelets. J. Thromb. Haemost. 2018, 16, 2300-2314. [CrossRef]

59. Schmitt, A.; Guichard, J.; Massé, J.M.; Debili, N.; Cramer, E.M. Of mice and men: Comparison of the ultrastructure of megakaryocytes and platelets. Exp. Hematol 2001, 29, 1295-1302. [CrossRef]

60. Nagao, R.J.; Marcu, R.; Wang, Y.; Wang, L.; Arakawa, C.; DeForest, C.; Chen, J.; López, J.A.; Zheng, Y. Transforming Endothelium with Platelet-Rich Plasma in Engineered Microvessels. Adv. Sci. 2019, 6, 1901725. [CrossRef]

61. Meyer, S.F.D.; Denorme, F.; Langhauser, F.; Geuss, E.; Fluri, F.; Kleinschnitz, C. Thromboinflammation in Stroke Brain Damage. Stroke 2016, 47, 1165-1172. [CrossRef]

62. Gao, C.; Wang, H.; Wang, T.; Luo, C.; Wang, Z.; Zhang, M.; Chen, X.; Tao, L. Platelet regulates neuroinflammation and restores blood-brain barrier integrity in a mouse model of traumatic brain injury. J. Neurochem. 2020, 154, 190-204. [CrossRef] [PubMed]

63. Leiter, O.; Walker, T.L. Platelets: The missing link between the blood and brain? Prog. Neurobiol. 2019, 183, 101695. [CrossRef]

64. Huber-Lang, M.; Lambris, J.D.; Ward, P.A. Innate immune responses to trauma. Nat. Immunol. 2018, 19, 327-341. [CrossRef] [PubMed]

65. Kazanis, I.; Feichtner, M.; Lange, S.; Rotheneichner, P.; Hainzl, S.; Öller, M.; Schallmoser, K.; Rohde, E.; Reitsamer, H.A.; CouillardDespres, S.; et al. Lesion-induced accumulation of platelets promotes survival of adult neural stem / progenitor cells. Exp. Neurol. 2015, 269, 75-89. [CrossRef] [PubMed]

66. Yonutas, H.M.; Hubbard, W.B.; Pandya, J.D.; Vekaria, H.J.; Geldenhuys, W.J.; Sullivan, P.G. Bioenergetic restoration and neuroprotection after therapeutic targeting of mitoNEET: New mechanism of pioglitazone following traumatic brain injury. Exp. Neurol. 2020, 327, 113243. [CrossRef]

67. Fuentes, M.; Araya-Maturana, R.; Palomo, I.; Fuentes, E. Platelet mitochondrial dysfunction and mitochondria-targeted quinoneand hydroquinone-derivatives: Review on new strategy of antiplatelet activity. Biochem. Pharmacol. 2018, 156, 215-222. [CrossRef]

68. Kilbaugh, T.J.; Lvova, M.; Karlsson, M.; Zhang, Z.; Leipzig, J.; Wallace, D.C.; Margulies, S.S. Peripheral Blood Mitochondrial DNA as a Biomarker of Cerebral Mitochondrial Dysfunction following Traumatic Brain Injury in a Porcine Model. PLoS ONE 2015, 10, e0130927. [CrossRef] [PubMed]

69. Ehinger, J.K.; Piel, S.; Ford, R.; Karlsson, M.; Sjövall, F.; Frostner, E.Å.; Morota, S.; Taylor, R.W.; Turnbull, D.M.; Cornell, C.; et al. Cell-permeable succinate prodrugs bypass mitochondrial complex I deficiency. Nat. Commun. 2016, 7, 12317. [CrossRef] [PubMed]

70. Corona de la Peña, N.; Gutiérrez-Aguilar, M.; Hernández-Reséndiz, I.; Marín-Hernández, Á.; Rodríguez-Enríquez, S. Glycoprotein $\mathrm{Ib}$ activation by thrombin stimulates the energy metabolism in human platelets. PLoS ONE 2017, 12, e0182374. [CrossRef] 